\title{
Review:
}

\section{Function, kinetic properties, crystallization, and regulation of microbial malate dehydrogenase*}

\author{
Tóshiko TAKAHASHI-ÍÑIGUEZ, Nelly ABURTO-RODRÍGUEZ, \\ Ana Laura VILCHIS-GONZÁLEZ, María Elena FLORES ${ }^{\dagger}$ \\ (Departamento de Biología Molecular y Biotecnología, Instituto de Investigaciones Biomédicas, \\ Universidad Nacional Autónoma de México, México, D.F. 04510, México) \\ †E-mail: mflores@biomedicas.unam.mx
}

Received Sept. 11, 2015; Revision accepted Dec. 14, 2015; Crosschecked Mar. 27, 2016

\begin{abstract}
Malate dehydrogenase $(\mathrm{MDH})$ is an enzyme widely distributed among living organisms and is a key protein in the central oxidative pathway. It catalyzes the interconversion between malate and oxaloacetate using NAD ${ }^{+}$ or $\mathrm{NADP}^{+}$as a cofactor. Surprisingly, this enzyme has been extensively studied in eukaryotes but there are few reports about this enzyme in prokaryotes. It is necessary to review the relevant information to gain a better understanding of the function of this enzyme. Our review of the data generated from studies in bacteria shows much diversity in their molecular properties, including weight, oligomeric states, cofactor and substrate binding affinities, as well as differences in the direction of the enzymatic reaction. Furthermore, due to the importance of its function, the transcription and activity of this enzyme are rigorously regulated. Crystal structures of MDH from different bacterial sources led to the identification of the regions involved in substrate and cofactor binding and the residues important for the dimer-dimer interface. This structural information allows one to make direct modifications to improve the enzyme catalysis by increasing its activity, cofactor binding capacity, substrate specificity, and thermostability. A comparative analysis of the phylogenetic reconstruction of $\mathrm{MDH}$ reveals interesting facts about its evolutionary history, dividing this superfamily of proteins into two principle clades and establishing relationships between MDHs from different cellular compartments from archaea, bacteria, and eukaryotes.
\end{abstract}

Key words: Malate dehydrogenase, Carbon metabolism, Tricarboxylic acid cycle http://dx.doi.org/10.1631/jzus.B1500219

CLC number: Q946.81 ${ }^{+} 8.3$

\section{Introduction}

The citric acid cycle is the central oxidative pathway in aerobic prokaryotes and eukaryotes (Sidhu et al., 2011). A key reaction of the cycle is the interconversion of malate and oxaloacetate catalyzed by $\mathrm{NAD}^{+}$- (EC 1.1.1.37) or $\mathrm{NADP}^{+}$-dependent (EC

\footnotetext{
Corresponding author

* Project supported by the Universidad Nacional Autónoma de MéxicoDirección General de Asuntos del Personal Académico-Programa de Apoyo a Proyectos de Investigación e Innovación Tecnológica (UNAMDGAPA-PAPIIT) (No. IN206313)

(D) ORCID: María Elena FLORES, http://orcid.org/0000-0001-8591-1855

(C) Zhejiang University and Springer-Verlag Berlin Heidelberg 2016
}

1.1.1.82) malate dehydrogenases (MDHs; L-malate: NAD oxidoreductase), which belong to the superfamily of 2-ketoacid NAD $(\mathrm{P})^{+}$-dependent dehydrogenases. In addition to their important metabolic role in aerobic energy production, they participate in diverse metabolic activities including aspartate biosynthesis, the malate-aspartate shuttle, gluconeogenesis, and lipogenesis (Labrou and Clonis, 1997).

$\mathrm{MDH}$ is a ubiquitous enzyme found in prokaryotic and eukaryotic organisms. MDHs from bacteria are less well studied and, unlike the enzyme from animals, they are heterogeneous in their molecular weight, subunit structure, and catalytic properties. In most eukaryotic cells, there are two major isozymes 
of $\mathrm{MDH}$, the cytosolic MDH and mitochondrial MDH However, in plants and some eukaryotic microorganisms, MDH isozymes are also present in other organelles such as glyoxysomes, chloroplasts, and peroxisomes (Gietl, 1992).

Based on sequence similarity, Goward and Nicholls (1994) suggested that MDH has diverged into two distinct phylogenetic groups. One group includes cytoplasmic $\mathrm{MDH}$, chloroplast $\mathrm{MDH}$, and MDH from Thermus flavus; the other group includes MDHs that are similar to lactate dehydrogenase (LDH) (Naterstad et al., 1996). This review is a comprehensive overview of the properties, function, crystallization, and evolution of the microbial MDHs.

\section{Molecular properties}

In the literature, there are relatively few reports on the molecular characteristics of bacterial MDHs. In prokaryotes, MDH can be found in two forms: homodimeric and tetrameric. Generally, this enzyme is found as a dimeric molecule in Gram-negative microorganisms, with a molecular weight between 30 and $38 \mathrm{kDa}$ for each monomer. Most Gram-positive bacteria and archaea had a tetrameric MDH (130 172 kDa), e.g. Bacillus spp. (Wynne et al., 1996), Mycobacterium tuberculosis (Öhman and Ridell, 1996), and Corynebacterium glutamicum (Molenaar et al., 1998). Other microorganisms such as Thermoactinomyces (Smith et al., 1984) and Salinibacter ruber (Madern and Zaccai, 2004) have a tetrameric MDH. In Beggiatoa leptomitiformis (Eprintsev et al., 2003), Rhodopseudomonas palustris (Eprintsev et al., 2008b), and Rhodobacter sphaeroides (Eprintsev et al. 2008a), both forms are present and are involved in different pathways. The dimeric form functions in the tricarboxylic acid (TCA) cycle and the tetrameric form functions in the citramalate or glyoxalate cycle (Table 1).

MDHs can be divided according to their preference for cofactors into $\mathrm{NAD}^{+}$-dependent $\mathrm{MDH}(\mathrm{EC}$ 1.1.1.37) and $\mathrm{NADP}^{+}$-dependent $\mathrm{MDH}$ (EC 1.1.1.82) and according to their preferences for oxaloacetate reduction over L-malate oxidation (Wang et al., 2011) Most bacterial MDHs have a strong preference for NADH; however, the C. glutamicum and T. flavus enzymes also exhibit some affinity for NADPH (Nishiyama et al., 1993; Molenaar et al., 1998). Archaeas contain NAD-MDHs, NADP-MDHs, or MDHs that have equal affinities for both cofactors (Nishiyama et al., 1993; Molenaar et al., 1998).

The reported Michaelis constant $\left(K_{\mathrm{m}}\right)$ values for oxaloacetate range from 20 to $189 \mu \mathrm{mol} / \mathrm{L}$ and for NADH range from 14 to $90 \mu \mathrm{mol} / \mathrm{L}$. The MDH affinities for L-malate and $\mathrm{NAD}^{+}$are lower than those for oxaloacetate; the $K_{\mathrm{m}}$ values for L-malate and $\mathrm{NAD}^{+}$range from 19 to $9000 \mu \mathrm{mol} / \mathrm{L}$ and from 24 to $1100 \mu \mathrm{mol} / \mathrm{L}$, respectively (Table 2).

The optimal $\mathrm{pH}$ for MDH for the reduction of oxaloacetate is $8.00-8.75$, whereas the oxidation of malate in Pseudomonas stutzeri has an optimal $\mathrm{pH}$ of 10.5 (Labrou and Clonis, 1997).

\section{Function of malate dehydrogenase}

$\mathrm{MDH}$ is an enzyme that catalyzes the interconversion between malate and oxaloacetate by using mostly $\mathrm{NAD}^{+} / \mathrm{NADH}$ as a cofactor. $\mathrm{MDH}$ is mainly involved in the oxidative TCA cycle (converting malate to oxaloacetate) even though the reaction that forms oxaloacetate is unfavorable under standard thermodynamic conditions. For this reason, it has been suggested that this enzyme has other functions inside the cell (Molenaar et al., 1998). MDH can participate in a reductive TCA cycle to protect against oxidative stress and also in the transport of substrates through the metabolic pathways. MDH from Escherichia coli grown under anaerobic conditions participates in a reductive TCA cycle (converting oxaloacetate to malate) that produces succinic acid ( $\mathrm{Wu}$ et al., 2007). Moreover, it participates in the protection against oxidative stress because oxaloacetate binds to free radicals (Oh et al., 2002). MDH, malic enzymes, and pyruvate carboxylase from Pseudomonas fluorescens are involved in an anti-oxidative pathway converting NADH, a pro-oxidant, into NADPH, an anti-oxidant (Singh et al., 2008).

The MDH protein in some microorganisms can interact with other TCA cycle enzymes to facilitate the substrate channeling, resulting in increased activity. For example, in Bacillus subtilis, MDH interacts with two TCA cycle enzymes, isocitrate dehydrogenase and citrate synthase, forming a metabolon (Meyer et al., 2011; Bartholomae et al., 2014). It has also been reported that $\mathrm{MDH}$ from $E$. coli interacts with complex I of the respiratory chain for the direct transfer of NADH (Amarneh and Vik, 2005). 
Table 1 Organization of malate dehydrogenases (MDHs) in microorganisms

\begin{tabular}{|c|c|c|}
\hline Microorganism & $\begin{array}{l}\text { Oligomeric state of MDH } \\
(\text { molecular weight }(\mathrm{kDa}))\end{array}$ & Reference \\
\hline $\begin{array}{l}\text { Deep-sea bacterium } \\
\quad \text { Photobacterium sp. strain SS9 }\end{array}$ & Monomer (37) & Welch and Bartlett, 1997 \\
\hline Aquaspirillium arcticum & Dimeric & Kim et al., 1999 \\
\hline Archaeoglobus fulgidus & Dimeric (70), monomer (31.9) & $\begin{array}{l}\text { Langelandsvik et al., 1997; Irimia et al., } \\
\quad 2004\end{array}$ \\
\hline Escherichia coli & Dimeric, monomer (30) & Vogel et al., 1987; Hall et al., 1992 \\
\hline Haemophilus parasuis & Dimeric (68.4), monomer (34.6) & Wise et al., 1997 \\
\hline Micropolyspora faeni & Dimeric & Smith et al., 1984 \\
\hline Pseudomonas indigofera & Dimeric & Sundaram et al., 1980 \\
\hline Pseudomonas stutzeri & Dimeric (66.5), monomer (34) & Labrou and Clonis, 1997 \\
\hline Rhodocyclus purpureus & Dimeric & Tayeh and Madigan, 1987 \\
\hline Sphaerotilus sp. strain D-507 & $\begin{array}{l}\text { Dimeric (organotrophic conditions), dimeric } \\
\text { or trimeric (mixotrophic conditions) }\end{array}$ & Eprintsev et al., 2009b \\
\hline Streptomyces aureofaciens & Dimeric (70), monomer (38) & Mikulášová et al., 1998 \\
\hline Streptomyces avermitilis & Dimeric, monomer (35) & Wang et al., 2011 \\
\hline Streptomyces coelicolor & Dimeric (73.3), monomer (36.7) & Ge et al., 2010 \\
\hline Streptomyces lividans & Dimeric & Smith et al., 1984 \\
\hline $\begin{array}{l}\text { Syntrophic propionate-oxidizing } \\
\text { bacterium strain MPOB }\end{array}$ & Dimeric (68), monomer (35) & van Kuijk and Stams, 1996 \\
\hline Thermomonospora chromogena & Dimeric & Smith et al., 1984 \\
\hline Thermomonospora fusca & Dimeric (65) & Sundaram et al., 1980 \\
\hline Thermus aquaticus & Dimeric & Sundaram et al., 1980 \\
\hline Thermus flavus & Dimeric & Kelly et al., 1993 \\
\hline Thermus thermophilus & Dimeric $(61)$ & Hung et al., 2013 \\
\hline $\begin{array}{l}\text { Sulfur bacterium Beggiatoa } \\
\text { leptomitiformis }\end{array}$ & $\begin{array}{l}\text { Tetrameric (172; glyoxalate cycle), dimeric } \\
\text { (Krebs cycle), } 4 \rightarrow 2 \text { depending on rate of } \\
\text { thiosulfate oxidation }\end{array}$ & Eprintsev et al., 2004 \\
\hline Aeropyrum pernix & Tetrameric (110), monomer (34) & Kawakami et al., 2009 \\
\hline Bacillus caldotenax & Tetrameric (130) & Smith et al., 1984 \\
\hline Bacillus subtilis & Tetrameric (140), monomer (33.6) & Sundaram et al., 1980 \\
\hline Chlorobium tepidum & Tetrameric & Dalhus et al., 2002 \\
\hline Chlorobium vibrioforme & Tetrameric & Dalhus et al., 2002 \\
\hline Chloroflexus aurantiacus & Tetrameric (35) & Rolstad et al., 1988; Dalhus et al., 2002 \\
\hline Corynebacterium glutamicum & Tetrameric (130), monomer (33) & Genda et al., 2003 \\
\hline Flavobacterium frigidimaris & Tetrameric & Fujii et al., 2007 \\
\hline Haloarcula marismortui & Tetrameric & Dym et al., 1995 \\
\hline Methanococcus jannaschii & Tetrameric & Lee et al., 2001 \\
\hline Mycobacterium tuberculosis & Tetrameric & Öhman and Ridell, 1996 \\
\hline Pyrobaculum islandicum & Tetrameric & Yennaco et al., 2007 \\
\hline Rhodobacter capsulatus & Tetrameric & Tayeh and Madigan, 1987 \\
\hline Rhodobacter sphaeroides & $\begin{array}{l}\text { Tetrameric (148; citramalate pathway), } \\
\text { dimeric ( } 74 ; \text { Krebs cycle) }\end{array}$ & Eprintsev et al., 2009a \\
\hline Rhodomicrobium vannielii & Tetrameric & Tayeh and Madigan, 1987 \\
\hline $\begin{array}{l}\text { Rhodopseudomonas palustris } \\
\text { strain f8pt }\end{array}$ & $\begin{array}{l}\text { Dimeric (Krebs cycle), tetrameric } \\
\text { (glyoxalate cycle) }\end{array}$ & Eprintsev et al., 2006 \\
\hline Rhodospirillum rubrum & Tetrameric & Tayeh and Madigan, 1987 \\
\hline $\begin{array}{l}\text { Extreme halophilic bacterium } \\
\text { Salinibacter ruber }\end{array}$ & Tetrameric (133), monomer (45) & Madern and Zaccai, 2004 \\
\hline Sulfolobus acidocaldarius & Tetrameric & Hartl et al., 1987 \\
\hline Thermoactinomyces candidus & Tetrameric & Smith et al., 1984 \\
\hline Thermoactinomyces sacchari & Tetrameric (130) & Sundaram et al., 1980 \\
\hline Thermoplasma acidophilum & Tetrameric & Grossebüter et al., 1986 \\
\hline
\end{tabular}




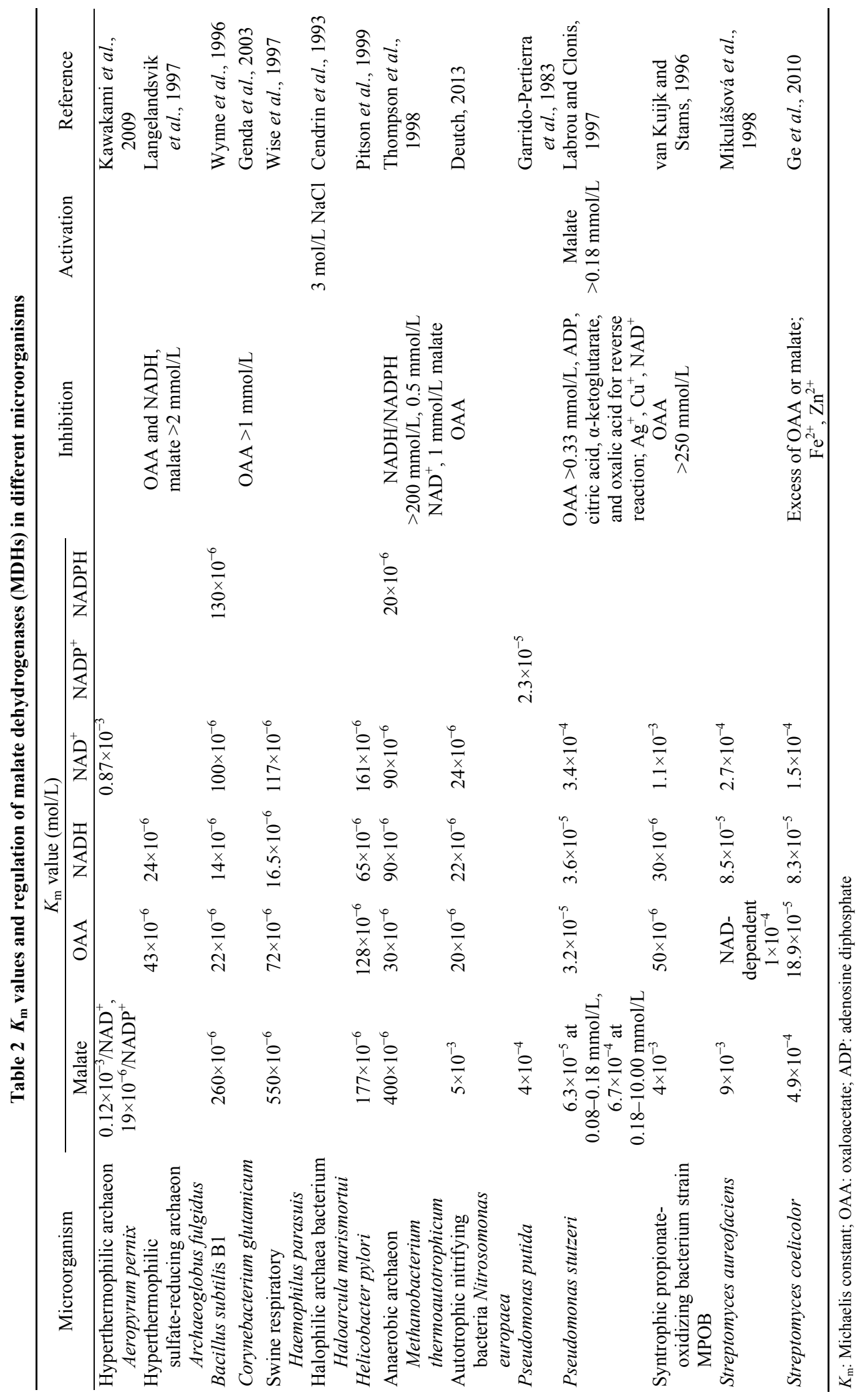


Several eukaryotic MDH isoforms are found in distinct cell organelles and are involved in diverse metabolic pathways (Gietl, 1992). In bacteria, the MDH isoforms are classified by their cofactor specificity or the number of subunits. In Methanobacterium thermoautotrophicum, there are two $\mathrm{MDH}$ isoforms; one of them has specificity for $\mathrm{NAD}^{+}$and catalyzes the interconversion of malate and oxaloacetate, and the other isoform can use either $\mathrm{NAD}^{+}$or $\mathrm{NADP}^{+}$, but it catalyzes only the reduction of oxaloacetate (Thompson et al., 1998). Two MDH isoforms have been characterized in $R$. sphaeroides $2 \mathrm{R}, R$. palustris $\mathrm{f}-8 \mathrm{pt}$, and $B$. leptomitiformis $\mathrm{D}-402$. The dimeric isoforms participate in the TCA cycle, and the tetrameric isoforms participate in the glyoxylate cycle (Eprintsev et al., 2004; 2008a; 2008b; 2009b).

\section{Malate:quinone oxidoreductase (MQO)}

Another enzyme, called malate:quinone oxidoreductase (MQO; EC 1.1.99.16), catalyzes the same reaction as MDH in Azotobacter (Jurtshuk et al., 1969), Mycobacterium (Yano et al., 2006), Micrococcus (Cohn, 1956), B. subtilis (Bergsma et al., 1982), C. glutamicum (Molenaar et al., 1998), E. coli (van der Rest et al., 2000), Pseudomonas aeruginosa (Kretzschmar et al., 2002), Pseudomonas citronellolis (Förster-Fromme and Jendrossek, 2005), and Helicobacter pylori (Kather et al., 2000). MQO is a membrane protein that catalyzes the oxidation of malate to oxaloacetate using $\mathrm{NAD}^{+}$as coenzyme and quinones as electron acceptors and the reaction is irreversible. Although both enzymes catalyze the same reaction, malate oxidation via $\mathrm{MQO}$ is more favorable (Gibbs free energy change $\left(\Delta G^{\circ}\right)=-55.0$ or $-18.9 \mathrm{~kJ} / \mathrm{mol})$ than that catalyzed by $\operatorname{MDH}\left(\Delta G^{\circ}=\right.$ $+28.6 \mathrm{~kJ} / \mathrm{mol}$ ). This observation suggests that if both enzymes are present at the same time, they will act in opposite directions (Molenaar et al., 2000).

In $E$. coli, the expression of the $m q o$ gene is regulated by carbon and energy sources and MQO activity was highest during exponential growth in pyruvate as a carbon source and declined after onset of the stationary phase, while MDH activity increased during the first $4 \mathrm{~h}$ and then remained between 2500 and $3000 \mathrm{nmol} /(\mathrm{mg} \cdot \mathrm{min})$. Both $m d h$ and $m q o$ genes are under the control of the ArcA-ArcB regulatory system (van der Rest et al., 2000). For C. glutamicum, it was reported that MQO is the principal enzyme catalyzing the oxidation of malate to oxaloacetate; by contrast, in E. coli, deletion of the mqo gene did not produce an effect on the growth rate, but deletion of the $m d h$ gene did (Molenaar et al., 2000; van der Rest et al., 2000).

The gene encoding MDH is absent in H. pylori. Therefore MQO is an important enzyme of the TCA cycle (Kather et al., 2000). On the other hand, Kretzschmar et al. (2002) reported that the mqo gene in $P$. aeruginosa is essential for growth on ethanol or acetate.

\section{Regulation of MDH activity}

MDH activity is regulated by feedback inhibition. Substrate inhibition studies have shown that MDH activity is strongly inhibited by excess of oxaloacetate and NADH. In some cases, high concentrations of malate can inhibit the reduction of oxaloacetate. The activation by L-malate has been reported in P. stutzeri (Labrou and Clonis, 1997) (Table 2). MDHs from Archaeoglobus fulgidus, Salinibacter ruber, and Saccharopolyspora erythraea are also inhibited by high oxaloacetate concentrations (Langelandsvik et al., 1997; Madern and Zaccai, 2004; Mendoza et al., 2009). In M. thermoautotrophicum, A. fulgidus, and $E$. coli, NADH has the same inhibitory effect (Langelandsvik et al., 1997; Thompson et al., 1998).

The carbon source or growth phase is another form of regulation. In C. glutamicum, both the succinate dehydrogenase and the MQO activities respond to the carbon source; their activities are 3.4 and 3.1 times higher in acetate than in glucose, respectively. $\mathrm{MDH}$ is also regulated in a similar way (Molenaar et al., 2000). When S. erythraea is grown in fructose, the MDH activity reaches its maximum value at $72-\mathrm{h}$ culture and then decreases; in contrast, the MDH activity remains constant throughout the culture when it is grown in glucose (Mendoza et al., 2009).

\section{Transcriptional regulation of $m d h$ gene}

The $m d h$ gene expression is regulated by carbon catabolic repression in several organisms. In Thermus 
thermophilus, MDH had a higher expression level when it was grown on malate as the carbon source instead of glucose (Park and Kilbane II, 2004). In addition, $m d h$ from $E$. coli is expressed at four-fold higher levels with pyruvate than with glucose under aerobic conditions (Park et al., 1995). When S. erythraea is grown in glucose, expression remains constant, whereas when grown in fructose, expression is induced (Mendoza et al., 2009). The $m d h$ expression can also be regulated by transcriptional factors. In $E$. coli, the expression is down-regulated by the aerobic respiration control protein (ArcA), particularly under anaerobic conditions (Park et al., 1995). When E. coli was grown on acid media, it raised not only the MDH activity but also the isocitrate dehydrogenase and succinate dehydrogenase activities (Jain et al., 2013).

\section{Crystallization, cofactor binding sites, and catalytic domains}

The MDHs from E. coli (Hall and Banaszak, 1993), T. flavus (Kelly et al., 1993), Haloarcula marismortui (Dym et al., 1995), A. fulgidus (Irimia et al., 2004), Methanococcus jannaschii (Lee et al., 2001), T. thermophilus (Chang et al., 2013), Flavobacterium frigidimaris (Fujii et al., 2007), and Streptomyces aureofaciens (Mernik et al., 1998) were crystallized.

MDHs display a high level of 3-dimensional structure similarity despite having a low identity in the amino acid sequence. Most of the prokaryotic forms are homologous to mitochondrial MDH; however, the MDH from T. flavus is homologous to that of eukaryotic cytoplasm (Kelly et al., 1993) and the $\mathrm{MDH}$ from T. thermophilus is most similar to the amino acid sequence of chloroplast NADP-dependent MDH (Hung et al., 2013).

When MDH is a dimeric protein, each subunit is composed of eleven $\beta$-sheets and nine to twelve $\alpha$-helices. It is folded into two domains: the N-terminal domain contains the cofactor binding site and the C-terminal domain contains the active site (Hung et al., 2013). In hyperthermophilic MDHs, the hydrophobic residues are mainly positioned in the protein core (Irimia et al., 2004) and an increase in the packing density decreases the protein volume (Dalhus et al., 2002).
The cofactor binding domain comprises six $\beta$-sheet strands surrounded by $\alpha$-helices in the $\mathrm{N}$-terminal domain. In proteins obtained from hyperthermophiles, the preferential use of NADPH as the cofactor is due to the presence of glycine at position 33 (Lee et al., 2001) and the dual specificity for the cofactor results from alanine at position 53 in Methanobacterium jannaschii (Kawakami et al., 2009). The $\mathrm{NAD}^{+}$specificity of hyperthermophilic Chloroflexus aurantiacus is determined by $\mathrm{Asp}^{32}$, which is similar to other MDHs in which the specificity is given by Asp or Glu (Dalhus et al., 2002).

The residues involved in NAD binding vary among MDHs. For example, in Aquaspirillium arcticum, this cofactor is bound to $\mathrm{Glu}^{43}, \mathrm{Gln}^{115}, \mathrm{Asn}^{134}$, $\mathrm{His}^{190}$, $\mathrm{Gly}^{12}, \mathrm{Gln}^{16}$, $\mathrm{Ile}^{17}, \mathrm{Val}^{132}$, and $\mathrm{Asn}^{134}$, and a loop formed by residues $90-100$ is also important (Kim et al., 1999). In E. coli, the ribose from $\mathrm{NAD}^{+}$interacts with residues $\mathrm{Gly}^{10}, \mathrm{Gly}^{11}, \mathrm{Ile}^{12}, \mathrm{Gly}^{78}, \mathrm{Val}^{79}$, $\mathrm{Asn}^{119}, \mathrm{Tyr}^{33}, \mathrm{Asp}^{34}, \mathrm{Ala}^{77}, \mathrm{Ile}^{97}, \mathrm{Leu}^{101}, \mathrm{Ser}^{76}, \mathrm{Il}^{117}$, $\mathrm{Val}^{146}$, and $\mathrm{Met}^{227}$. The cofactor binding site has a positive charge, whereas the rest of the protein is negatively charged (Hall and Banaszak, 1993). Similarly, nicotinamide binds to the hydrophobic cleft of MDH from T. flavus composed of $\mathrm{Leu}^{40}, \mathrm{Ile}^{42}, \mathrm{Il}^{107}$, $\mathrm{Thr}^{9}, \mathrm{Gly}^{10}, \mathrm{Gly}^{87}$, and $\mathrm{Ala}^{88}$ (Kelly et al., 1993). In M. jannaschii, $\mathrm{NADP}^{+}$binds to $\mathrm{Ser}^{9}, \mathrm{Arg}^{34}, \mathrm{His}^{36}$, $\mathrm{Ser}^{37}, \mathrm{Ile}^{121}, \mathrm{Asn}^{123}$, and $\mathrm{Glu}^{219}$ (Lee et al., 2001). Finally, in C. aurantiacus, the adenine ring is positioned between $\mathrm{Val} / \mathrm{Ile}$ at position 33 and Ala/Ser at position 77 , and forms a hydrogen bond to $\mathrm{Glu}^{100}$ and two hydrogen bonds to $\mathrm{Asp}^{32}$, which clearly distinguishes the specificity for NAD relative to NADP (Dalhus et al., 2002).

In 2005, an MDH-NADPH complex from T. flavus was crystallized. The coenzyme interacted with the same amino acid residues as those involved in NADH binding; however, the nicotinamide was bound in the opposite orientation. This complex had two Tris molecules near the active site, which are necessary to stabilize the complex but not for cofactor binding in the reverse orientation (Tomita et al., 2005).

The catalytic domain consists of five antiparallel twisted $\beta$-sheets surrounded by eight $\alpha$-helices in T. thermophilus (Hung et al., 2013). It has been reported that oxaloacetate and NAD do not interact directly and oxaloacetate binding does not induce any conformational changes in protein structure in 
A. arcticum (Kim et al., 1999). In addition, substrate specificity is provided by an arginine residue near position 100 (Dym et al., 1995; Lee et al., 2001; Kawakami et al., 2009). In $A$. arcticum, the residues important for oxaloacetate binding are $\mathrm{Arg}^{165}$, His ${ }^{190}$, $\mathrm{Ser}^{241}, \mathrm{Arg}^{229}$, and $\mathrm{Gly}^{230}$ (Kim et al., 1999). In E. coli, $\mathrm{Arg}^{81}$ is in the NAD binding domain, and $\mathrm{Arg}^{153}$ is present at the catalytic site (Hall et al., 1992).

In $A$. arcticum and $M$. jannaschii, the active site of the protein is in the middle of the cofactor binding site and the substrate binding site placed between residues 87-92 (Kim et al., 1999; Lee et al., 2001). MDHs possess conserved catalytic residues, including $\mathrm{Arg}^{92}, \mathrm{Asp}^{151}, \mathrm{His}^{178}{ }^{17} \mathrm{Arg}^{154}, \mathrm{Arg}^{102}, \mathrm{Arg}^{109}, \mathrm{Asp}^{168}$, $\mathrm{Arg}^{171}$, and His ${ }^{195}$ in Aeropyrum pernix (Kawakami et al., 2009). In T. flavus, the Asn ${ }^{130}$, His ${ }^{186}, \mathrm{Asp}^{158}$, and $\mathrm{Arg}^{161}$ residues compose the active site (Kelly et al., 1993), and in H. marismortui, $\mathrm{Arg}^{100}, \mathrm{Arg}^{169}$, and $\mathrm{Arg}^{171}$ are in conserved regions that constitute this site (Dym et al., 1995). In both dimeric and tetrameric MDHs, the His ${ }^{174}-\mathrm{Asp}^{147}$ pair and $\mathrm{Arg}^{150}$ are essential for substrate binding and catalysis (Dalhus et al., 2002).

The dimeric interface consists of two pairs of five helices in E. coli (Hall et al., 1992) and in $T$. thermophilus is about $1619 \AA$ and involves 18 hydrogen bonds and extensive hydrophobic interactions (Hung et al., 2013). In A. arcticum it is formed from helices $\alpha 1, \alpha 2$, and $\alpha 9-\alpha 10$ (Kim et al., 1999). In $C$. aurantiacus $\mathrm{MDH}$, residues His ${ }^{17}$ and $\operatorname{Trp}^{18}$ of each monomer are intercalated to form a "zipper" between the monomers. Some of the main differences between the tetrameric and dimeric MDHs with respect monomer-monomer interactions are found in regions 190-196 and 241-245 (Dalhus et al., 2002).

In tetrameric MDHs, the dimer-dimer interface is composed of regions 188-192 and 241-246, which fit well into crevices on the opposite dimer. The molecular packing around the 190-195 loop in tetrameric MDHs is different from that of dimeric MDHs (Dalhus et al., 2002). Additionally, in a halophilic $\mathrm{MDH}$, salt bridges are observed at the dimer-dimer interface (Dym et al., 1995).

\section{Improvements to the enzyme malate de- hydrogenase activity}

Studying thermophilic bacteria is important because they are a source for hyperthermophilic enzymes, which have multiple applications in biotechnology processes. Furthermore, identifying the amino acids involved in stability and defining their influence on kinetic parameters allows us to make specific changes that improve their characteristics and expand their potential applications. In this regard, the genus Thermus has been extensively studied. MDH from $T$. flavus was one of the first heat-stable enzymes described (Kelly et al., 1993).

Nishiyama et al. (1986) cloned, sequenced, purified, and described the kinetic parameters of wild-type MDH from $T$. flavus AT-62. A multiple alignment between MDHs from different sources (Fernley et al., 1981; Birktoft et al., 1982; Birktoft and Banaszak, 1983) enabled them to determine the conserved regions involved in catalytic function (Asp ${ }^{152}$ and His ${ }^{180}$ ), a nucleotide binding domain (six parallel $\beta$-sheets in $\mathrm{NH}_{2}$ terminal) and several $\alpha$-helices involved in the interactions between subunits $\left(\mathrm{Glu}^{51}-\mathrm{Leu}^{65}\right)$. They also cloned, sequenced, and described a mutant version of $\mathrm{MDH}$ from the same organism. The exchange of one residue (Thr190Ile) in the amino acid sequence causes large changes in the kinetic parameters, including a decrease in the inhibitory effect by oxaloacetate, an increase in catalytic rate constant $\left(K_{\text {cat }}\right)$ and $K_{\mathrm{m}}$ for oxaloacetate, a more acidic optimum $\mathrm{pH}$ activity, and a reduction in heat stability (Nishiyama et al., 1991).

In a later work, the same authors explored the enzymatic contribution of $\mathrm{Thr}^{190}$ to the kinetic parameters by making a series of substitutions at this position with all other amino acids using site-directed mutagenesis. Most of the substitutions evaluated showed an increase in inhibition constant $\left(K_{\mathrm{i}}\right)$ and $K_{\mathrm{m}}$ for oxaloacetate and $K_{\text {cat }}$. The changes in sensitivity to substrate inhibition are attributed to the changes in $K_{\mathrm{m}}$ for oxaloacetate (Nishiyama et al., 1991). An analysis of the 3-dimensional structure of porcine heart cytoplasmic MDH shows important residues forming hydrogen bonds around the catalytic loop. These residues are identical or similar in the Thermus $\mathrm{MDH}$ and all of them confer stability to the structure minimizing the effects of changes from other amino acids at this position. The changes to Pro and His resulted in the highest $K_{\mathrm{m}}$ values and the greatest loss of substrate inhibition (Nishiyama et al., 1991). Similar approaches were performed to determine the amino acids involved in substrate specificity. It has been reported that one change in the amino acid sequence (Gln102Arg) between lactate and MDHs from E. coli 
can convert the specificity of the enzyme from pyruvate to oxaloacetate (Wilks et al., 1988). However, the same modification made to its malate counterpart (Arg102Gln) does not change its specificity from oxaloacetate to pyruvate; it merely decreases its selectivity. The mutation also reduces the enzyme's relative binding energy for oxaloacetate by about $7 \mathrm{kcal} / \mathrm{mol}$. These effects are due to weaker interactions (hydrogen bonds) within the carboxylate group of the substrate with Gln in mutant MDH compared with Arg (salt bridge) in the wild-type version (Nicholls et al., 1992).

Using crystallographic evidence, Nishiyama et al. (1993) hypothesize that 7 residues inside a $\beta B-\alpha C$ loop of $\mathrm{MDH}$ are responsible for the cofactor specificity. Using directed mutagenesis in T. flavus NADH-MDH, they purified the EX7 mutant, which has 7 residues $\left(\mathrm{Glu}^{41}-\mathrm{Met}^{47}\right)$ replaced by the corresponding residues in the NADPH-MDH of chloroplast. This EX7 mutant enzyme had a 27-fold higher $K_{\mathrm{m}}$ for NADH and a 7-fold higher catalytic efficiency with NADPH than the wild-type enzyme, but a $K_{\mathrm{m}}$ for NADPH $1 / 8$ and a catalytic efficiency with NADH 1/71 of the size of the wild-type enzyme, changing the coenzyme specificity. To identify residues responsible for the coenzyme specificity, they mutated three residues and purified the mutant enzyme EX3, which exhibited similar effects in kinetic parameters, but a decreased $K_{\mathrm{m}}$ for oxaloacetate in presence of NADPH.

When a thermostable enzyme is not from a thermophilic organism, different approaches have been made to achieve enzymatic stability, such as modifying the residues involved in stability without affecting its catalytic efficiency. An example of this approach is the mutant $\mathrm{MDH}$ protein from E. coli (R102Q), which shows a higher thermal stability because the mutated residues are on a mobile loop causing the loop to remain closed in the structure, preventing collisional energy transfer from the solvent. Because this mutation results in a different tertiary structure of the enzyme, the kinetic parameters were affected (Goward et al., 1994).

Nishiyama et al. (1996) made another type of improvement to the MDH enzyme. Using chemical mutagenesis, they obtained a mutant MDH with Thr189Ile, a mutation that increases its enzymatic activity. The $\mathrm{Thr}^{189}$ residue was replaced by the other 18 amino acids, and the mutant enzymes showed the same results as with Thr189Ile. This residue is close to His ${ }^{186}$ and both belong to a hydrogen bond network around the catalytic site. The substitutions at this position cause the loss of at least two hydrogen bonds, increasing the flexibility at the catalytic site resulting in an increase in enzymatic activity.

Bioinformatics approaches have also been used to improve the stability of enzymes. An example is the work of Kono et al. (1997), who developed computational programs to predict mutations in the amino acid sequence of MDH that conferred more thermal stability taking into consideration folded and unfolded states, entropic contributions and van der Waals energy, as well as side-chain packing of the hydrophobic core, hydration, and side chain entropy (Kono et al., 1998). Their model predicted the amino acid positions and identified V169L and the double mutants V169L/V199I and V169L/V199M as substitutions that would enhance enzyme stability (Kono et al., 1997). The stability of the variant proteins predicted by the programs was consistent with that obtained experimentally (Kono et al., 1998).

\section{Molecular evolution of bacterial malate dehydrogenase}

Because of its important catalytic role in metabolism, it is not surprising that the MDH enzyme is ubiquitously found in organisms throughout the different domains of life. The current accessibility of the amino acid sequences deposited in public databases has allowed not only the determination of the important residues and domains involved in its function and catalysis but also the elucidation of evolutionary relationships among species.

One of the first comparative analyses for the phylogenetic reconstruction of MDH was performed by McAlister-Henn (1988). In this study, the MDH amino acid sequences of different cellular compartments (cytoplasm and mitochondria) were used. This analysis showed that their folding and catalytic mechanisms were similar as well as their kinetic properties. However, they have low similarity in amino acid sequence. These differences are noticeable when isoenzymes from the same compartments between different organisms are compared. Contrasting results are observed from the comparison 
between mitochondrial versus bacterial $\mathrm{MDH}$, obtaining highly conserved substrate $(71 \%)$ and cofactor $(80 \%)$ domains. This indicates that the mitochondrial enzyme is more closely related to its prokaryotic counterpart than to its cytoplasmic counterpart, supporting the endosymbiotic theory of the origin of mitochondrial evolution.

General approaches where complete genomes of different species are studied enable the identification of the presence of genes encoding proteins involved in specific metabolic pathways in the cell. In this type of study, the absence of genes is also informative because one can infer that some organisms do not have a particular route or suffer some adaptations to cover these gaps in metabolism. A study to elucidate the evolution of the TCA cycle, which included the complete genome of organisms from the three domains of life, showed that only the larger bacterial genomes (E. coli, B. subtilis, M. tuberculosis, and Rickettsia prowazekii) have the ability to run the complete cycle. In the genomes of some organisms, the cycle is interrupted, or, in some cases, is missing completely. The MDH reaction is conserved in the majority of species evaluated, including those whose cycles are incomplete. This conservation may be by functional replacement via non-homologous gene displacement (Huynen et al., 1999; Koonin and Galperin, 2003).

Homo-oligomeric proteins are a source of diversity and structural specificity under intensive study for a better understanding of their functional roles in providing stability and protection against denaturation and for the elucidation of the mechanisms involved in the evolution of structure-function (Hashimoto and Panchenko, 2010). In this regard, the MDH enzyme has been widely used as a model because of its presence in different subcellular compartments and as different functional oligomeric states (dimers or tetramers). Structural alignments of four crystals reported for the cytoplasmic and mitochondrial MDH from eukaryote (pig) and two prokaryotic proteins $(E$. coli and $T$. flavus) were performed to determine the site critical for dimer formation. As expected, mutants in this site (D45Y) in E. coli promote the dissociation of the dimer. This purified mutant protein is monomeric and displays $1 / 14000$ the enzymatic activity of the wild type, with altered kinetic parameters that show a reduced affinity for both its substrate and cofactor. This evidence supports the reciprocating compulsory order mechanism model, in which the subunits alternate between two roles, as an active subunit or as a helper subunit. From this model, it may be inferred that the monomers are inactive (Breiter et al., 1994; Musrati et al., 1998).

Evolutionary studies of ancient organisms such as archaea have led to the establishment of phylogenetic relationships between MDHs and LDHs due to greater similarity between these families than within the MDHs from different compartments in the cell. The process of evolution involved in the explanation of these differences is the ancestral duplication of the $m d h$ gene prior to the invasion of primordial eukaryotes by bacteria, the origin of mitochondria (Goward and Nicholls, 1994). The catalytic and cofactor binding domains between these two protein families are highly conserved. In both cases, the catalytic site is a hydrophobic pocket that contains both domains. Binding the substrate and the cofactor changes the protein structure, including the movement of an external loop that seals the catalytic site and positions the active residues involved in catalysis closer together through a proton relay system (Goward and Nicholls, 1994).

The integration of the information generated from biochemical parameters, structural determinations, and bioinformatics data has enabled a more detailed reconstruction of the evolutionary history of the MDH family. The phylogenetic tree based on the enzymatic function divides the superfamily into the $\mathrm{MDH}$ and LDH groups as previously reported (Goward and Nicholls, 1994). When this tree was analyzed with reference to the oligomeric state, the superfamily is divided into the first two groups plus a third group comprising the proteins whose sequences correspond to $\mathrm{MDH}$ and that are similar to the proteins in the LDH group. This third group has been named the tetrameric [LDH-like]L-MDH (Madern, 2002).

A distinctive feature of this new group is the presence of an Arg and a Pro at the 102 and 250 positions, respectively. The latter residue is an Ile in LDHs and a Ser in dimeric MDHs. In agreement with previous analysis (Goward and Nicholls, 1994), the MDH group is separated into two clades. The first clade includes mitochondrial MDHs as well as the glycosomal MDHs, suggesting an inherited from a mitochondrial gene duplication and then a subsequent acquisition of the signal sequence. The other clade includes cytoplasmic and chloroplast MDHs. With all 
of these data, it is presumed that the ancestral gene encodes for [LDH-like]L-MDH and underwent a genetic duplication giving rise to two copies. This first event of duplication is associated with changes in oligomeric states that modified the biochemical properties without affecting function. One copy evolved into the dimeric MDHs from which the two versions that correspond to cytosolic and mitochondrial clades were generated. The other tetrameric copy originating from the first gene duplication underwent a second duplication during its evolution which is associated to changes in function; one of them became the LDH group and the other one remained as an [LDH-like]L-MDH protein. In contrast to previous work (Gray et al., 1999; Karlberg et al., 2001), Madern (2002) proposes an endosymbiotic origin for the [LDH-like]L-MDH group, while the presence of dimeric MDHs in eukaryotes is better explained by cryptic endosymbiosis, lateral gene transfer, or the presence of a pre-existing gene in a protoeukaryotic ancestor.

All these studies from which the structural and functional characteristics of the $\mathrm{MDH}$, as well as the information about their evolutionary history, are derived, have turned this enzyme into a tool for the reconstruction of genealogies. MDH was selected as a molecular marker from a variety of enzymes to determine differences in inter- and intra-species in microbial source tracking assays (Ivanetich et al., 2006). Likewise, this enzyme was used as a marker to obtain the phylogeny of $\gamma$-proteobacteria, a group known to be taxonomically complex (Farfán et al., 2010).

\section{Conclusions}

The TCA cycle is the most important metabolic pathway for supplying adenosine triphosphate (ATP) to aerobic organisms. MDH is one of the last enzymes in this cycle and carries out the interconversion between malate and oxaloacetate employing either $\mathrm{NAD}^{+}$or $\mathrm{NADP}^{+}$as a cofactor. In prokaryotes, this enzyme can be found in homodimeric or tetrameric forms, ranging from 30 to $38 \mathrm{kDa}$ per monomer. There are $\mathrm{NAD}^{+}$- or $\mathrm{NADP}^{+}$-dependent enzymes and, in some organisms, the enzymes can bind both cofactors with the same affinity. From the kinetic data, we observed a great variation among the $K_{\mathrm{m}}$ values reported for substrate and cofactor.
It has been suggested that MDH can participate in a reductive TCA cycle and can function as a substrate-delivering enzyme to other members of this cycle. Being a ubiquitous enzyme, its function has to be precisely regulated. MDH suffers feedback inhibition and is inhibited by high concentrations of oxaloacetate and NADH, and, in some cases, malate. At the transcriptional level, $m d h$ gene expression is regulated by carbon catabolic repression. However, in some organisms, its expression is induced by certain carbon sources such as fructose.

MDH shows a highly conserved 3-dimensional structure despite having a low identity in the amino acid sequence. The cofactor binding domain is in the $\mathrm{N}$-terminal domain of the protein and the presence of a specific amino acid at certain positions defines the $\mathrm{NAD}^{+}$or $\mathrm{NADP}^{+}$binding specificity. The substrate binding domain contains similar catalytic residues that form the most highly conserved region of the protein between species. Substrate binding does not induce a significant change in the structure and the substrate does not interact with the cofactor.

The determination of the tertiary structure of MDH from hyperthermophilic organisms allowed for improvements by direct mutagenesis of the enzyme. These mutations yielded an enzyme with increased affinity for its cofactor, increased stability, and improved catalytic activity. Thus, an enzyme suitable for many biotechnological applications was generated.

MDH is widely distributed among living organisms, and all the reported data made the reconstruction of its evolutionary history possible. LDHs and MDHs are the two principal groups that form the superfamily. A closer examination of the MDH clade shows a close relation among bacterial and mitochondrial enzymes, reinforcing the endosymbiotic evolution theory. In addition to these two groups, a more detailed analysis took into consideration the oligomeric state, biochemical parameters, and enzymatic function, resulting in another group within the $\mathrm{MDH}$ and LDH superfamily, the [LDH-like]L-MDH group. It is presumed that the ancestor gene of this superfamily was derived from this group.

\section{Compliance with ethics guidelines}

Tóshiko TAKAHASHI-ÍÑIGUEZ, Nelly ABURTORODRÍGUEZ, Ana Laura VILCHIS-GONZÁLEZ, and María Elena FLORES declare that they have no conflict of interest. 
This article does not contain any studies with human or animal subjects performed by any of the authors.

\section{References}

Amarneh, B., Vik, S.B., 2005. Direct transfer of NADH from malate dehydrogenase to complex I in Escherichia coli. Cell Biochem. Biophys., 42(3):251-262. http://dx.doi.org/10.1385/CBB:42:3:251

Bartholomae, M., Meyer, F., Commichau, F., et al., 2014. Complex formation between malate dehydrogenase and isocitrate dehydrogenase from Bacillus subtilis is regulated by tricarboxylic acid cycle metabolites. FEBS J., 281(4):1132-1143. http://dx.doi.org/10.1111/febs.12679

Bergsma, J., van Dongen, M.B., Konings, W.N., 1982. Purification and characterization of NADH dehydrogenase from Bacillus subtilis. Eur. J. Biochem., 128(1):151-157. http://dx.doi.org/10.1111/j.1432-1033.1982.tb06945.x

Birktoft, J., Banaszak, L., 1983. The presence of a histidineaspartic acid pair in the active site of 2-hydroxyacid dehydrogenases. X-ray refinement of cytoplasmic malate dehydrogenase. J. Biol. Chem., 258(1):472-482.

Birktoft, J., Fernley, R., Bradshaw, R., et al., 1982. Amino acid sequence homology among the 2-hydroxy acid dehydrogenases: mitochondrial and cytoplasmic malate dehydrogenases form a homologous system with lactate dehydrogenase. PNAS, 79(20):6166-6170. http://dx.doi.org/10.1073/pnas.79.20.6166

Breiter, D.R., Resnik, E., Banaszak, L.J., 1994. Engineering the quaternary structure of an enzyme: construction and analysis of a monomeric form of malate dehydrogenase from Escherichia coli. Protein Sci., 3(11):2023-2032. http://dx.doi.org/10.1002/pro.5560031115

Cendrin, F., Chroboczek, J., Zaccai, G., et al., 1993. Cloning, sequencing, and expression in Escherichia coli of the gene coding for malate dehydrogenase of the extremely halophilic archaebacterium Haloarcula marismortui. Biochemistry, 32(16):4308-4313. http://dx.doi.org/10.1021/bi00067a020

Chang, Y.Y., Hung, C.H., Hwang, T.S., et al., 2013. Cloning, overexpression, purification and crystallization of malate dehydrogenase from Thermus thermophilus. Acta Crystallogr. Sect. F Struct. Biol. Cryst. Commun., 69(Pt 11): 1249-1251. http://dx.doi.org/10.1107/S174430911302472X

Cohn, D.V., 1956. The oxidation of malic acid by Micrococcus lysodiekticus. J. Biol. Chem., 221(1):413-423.

Dalhus, B., Saarinen, M., Sauer, U.H., et al., 2002. Structural basis for thermophilic protein stability: structures of thermophilic and mesophilic malate dehydrogenases. $J$. Mol. Biol., 318(3):707-721. http://dx.doi.org/10.1016/S0022-2836(02)00050-5

Deutch, C.E., 2013. L-Malate dehydrogenase activity in the reductive arm of the incomplete citric acid cycle of $\mathrm{Ni}$ trosomonas europaea. Antonie van Leeuwenhoek, 104(5):
645-655.

http://dx.doi.org/10.1007/s10482-013-9973-6

Dym, O., Mevarech, M., Sussman, J.L., 1995. Structural features that stabilize halophilic malate dehydrogenase from an archaebacterium. Science, 267(5202):1344-1346. $\mathrm{http}: / / \mathrm{dx}$.doi.org/10.1126/science.267.5202.1344

Eprintsev, A.T., Falaleeva, M.I., Stepanova, I.Y., et al., 2003. Purification and physicochemical properties of malate dehydrogenase from bacteria of the genus Beggiatoa. Biochemistry (Moscow), 68(2):172-176. http://dx.doi.org/10.1023/A:1022693211134

Eprintsev, A.T., Falaleeva, M.I., Grabovich, M.I., et al., 2004. Role of malate dehydrogenase isoforms in the regulation of anabolic and catabolic processes in the colorless sulfur bacterium Beggiatoa leptomitiformis D-402. Mikrobiologiia, 73(4):367-371 (in Russian).

Eprintsev, A.T., Falaleeva, M.I., Klimova, M.A., et al., 2006. Physicochemical properties of malate dehydrogenase from the bacterium Rhodopseudomonas palustris strain f8pt. Biochemistry (Moscow), 71(6):692-695. http://dx.doi.org/10.1134/S0006297906060149

Eprintsev, A.T., Klimova, M.A., Shikhalieva, K.D., et al., 2008a. Isolation and purification of malate dehydrogenase isoforms from phototrophic purple bacteria Rhodobacter sphaeroides and Rhodopseudomonas palustris. Izv. Akad. Nauk. Ser. Biol., 6:680-687 (in Russian).

Eprintsev, A.T., Klimova, M.A., Falaleeva, M.I., et al., 2008b. Regulation of carbon flows in the tricarboxylic acid cycle-glyoxylate bypass system in Rhodopseudomonas palustris under different growth conditions. Mikrobiologiia, 77(2):132-136 (in Russian).

Eprintsev, A.T., Klimova, M.A., Shikhalieva, K.D., et al., 2009a. Features of structural organization and expression regulation of malate dehydrogenase isoforms from Rhodobacter sphaeroides strain 2R. Biochemistry (Moscow), 74(7):793-799.

http://dx.doi.org/10.1134/S000629790907013X

Eprintsev, A.T., Falaleeva, M.I., Arabtseva, M.A., et al., $2009 \mathrm{~b}$. Structural-functional transformation of the malate dehydrogenase system of the bacterium Sphaerotilus sp. strain D-507 depending on nutritional mode. Biol. Bull., 36(3):220-226. http://dx.doi.org/10.1134/S1062359009030029

Farfán, M., Miñana-Galbis, D., Garreta, A., et al., 2010. Malate dehydrogenase: a useful phylogenetic marker for the genus Aeromonas. Syst. Appl. Microbiol., 33(8):427-435. http://dx.doi.org/10.1016/j.syapm.2010.09.005

Fernley, R., Lentz, S., Bradshaw, R., 1981. Malate dehydrogenase: isolation from Escherichia coli and comparison with the eukaryotic mitochondrial and cytoplasmic forms. Biosci. Rep., 1(6):497-507. http://dx.doi.org/10.1007/BF01121583

Förster-Fromme, K., Jendrossek, D., 2005. Malate:quinone oxidoreductase $(\mathrm{MqoB})$ is required for growth on acetate and linear terpenes in Pseudomonas citronellolis. FEMS 
Microbiol. Lett., 246(1):25-31.

http://dx.doi.org/10.1016/j.femsle.2005.03.034

Fujii, T., Oikawa, T., Muraoka, I., et al., 2007. Crystallization and preliminary X-ray diffraction studies of tetrameric malate dehydrogenase from the novel Antarctic psychrophile Flavobacterium frigidimaris KUC-1. Acta Crystallogr. Sect. F Struct. Biol. Cryst. Commun., 63(Pt 11):983-986. http://dx.doi.org/10.1107/S1744309107051524

Garrido-Pertierra, A., Martinez, M.C., Fernández, M., et al., 1983. Properties and function of malate enzyme from Pseudomonas putida. Biochimie, 65(11-12):629-635.

Ge, Y.D., Cao, Z.Y., Wang, Z.D., et al., 2010. Identification and biochemical characterization of a thermostable malate dehydrogenase from the mesophile Streptomyces coelicolor A3(2). Biosci. Biotechnol. Biochem., 74(11): 2194-2201. http://dx.doi.org/10.1271/bbb.100357

Genda, T., Nakamatsu, T., Ozak, H., 2003. Purification and characterization of malate dehydrogenase from Corynebacterium glutamicum. J. Biosci. Bioeng., 95(6):562-566. http://dx.doi.org/10.1016/S1389-1723(03)80162-7

Gietl, C., 1992. Malate dehydrogenase isoenzymes: cellular locations and role in the flow of metabolites between the cytoplasm and cell organelles. Biochim. Biophys. Acta, 1100(3):217-234. http://dx.doi.org/10.1016/0167-4838(92)90476-T

Goward, C.R., Nicholls, D.J., 1994. Malate dehydrogenase: a model for structure, evolution, and catalysis. Protein Sci., 3(10):1883-1888. http://dx.doi.org/10.1002/pro.5560031027

Goward, C., Miller, J., Nicholls, D., et al., 1994. A single amino acid mutation enhances the thermal stability of Escherichia coli malate dehydrogenase. Eur. J. Biochem., 224(1):249-255. http://dx.doi.org/10.1111/j.1432-1033.1994.tb20018.x

Gray, M.W., Burger, G., Lang, B.F., 1999. Mitochondrial evolution. Science, 283(5407):1476-1481. http://dx.doi.org/10.1126/science.283.5407.1476

Grossebüter, W., Hartl, T., Görisch, H., et al., 1986. Purification and properties of malate dehydrogenase from the thermoacidophilic archaebacterium Thermoplasma acidophilum. Biol. Chem. Hoppe-Seyler, 367(1):457-463. http://dx.doi.org/10.1515/bchm3.1986.367.1.457

Hall, M.D., Banaszak, L.J., 1993. Crystal structure of a ternary complex of Escherichia coli malate dehydrogenase citrate and NAD at $1.9 \AA$ resolution. J. Mol. Biol., 232(1): 213-222.

http://dx.doi.org/10.1006/jmbi.1993.1377

Hall, M.D., Levitt, D.G., Banaszak, L.J., 1992. Crystal structure of Escherichia coli malate dehydrogenase. A complex of the apoenzyme and citrate at $1.87 \AA$ resolution. $J$. Mol. Biol., 226(3):867-882.

http://dx.doi.org/10.1016/0022-2836(92)90637-Y

Hartl, T., Grossebüter, W., Görisch, H., et al., 1987. Crystalline NAD/NADP-dependent malate dehydrogenase; the enzyme from the thermoacidophilic archaebacterium Sulfolobus acidocaldarius. Biol. Chem. Hoppe-Seyler, 368(1): 259-267. http://dx.doi.org/10.1515/bchm3.1987.368.1.259

Hashimoto, K., Panchenko, A.R., 2010. Mechanisms of protein oligomerization, the critical role of insertions and deletions in maintaining different oligomeric states. PNAS, 107(47):20352-20357. http://dx.doi.org/10.1073/pnas.1012999107

Hung, C.H., Hwang, T.S., Chang, Y.Y., et al., 2013. Crystal structures and molecular dynamics simulations of thermophilic malate dehydrogenase reveal critical loop motion for co-substrate binding. PLOS ONE, 8(12):e83091. http://dx.doi.org/10.1371/journal.pone.0083091

Huynen, M.A., Dandekar, T., Bork, P., 1999. Variation and evolution of the citric-acid cycle: a genomic perspective. Trends Microbiol., 7(7):281-291. http://dx.doi.org/10.1016/S0966-842X(99)01539-5

Irimia, A., Vellieux, F.M.D., Madern, D., et al., 2004. The $2.9 \AA$ resolution crystal structure of malate dehydrogenase from Archaeoglobus fulgidus: mechanisms of oligomerization and thermal stabilisation. J. Mol. Biol., 335(1):343-356. http://dx.doi.org/10.1016/j.jmb.2003.10.054

Ivanetich, K.M., Hsu, P.H., Wunderlich, K.M., et al., 2006. Microbial source tracking by DNA sequence analysis of the Escherichia coli malate dehydrogenase gene. J. Microbiol. Methods, 67(3):507-526. http://dx.doi.org/10.1016/j.mimet.2006.04.026

Jain, P.K., Jain, V., Singh, A.K., et al., 2013. Evaluation on the responses of succinate dehydrogenase, isocitrate dehydrogenase, malate dehydrogenase and glucose-6-phosphate dehydrogenase to acid shock generated acid tolerance in Escherichia coli. Adv. Biomed. Res., 2(3):75-85. http://dx.doi.org/10.4103/2277-9175.115799

Jurtshuk, P., Bednarz, A.J., Zei, P., et al., 1969. L-Malate oxidation by the electron transport fraction of Azotobacter vinelandii. J. Bacteriol., 98(3):1120-1127.

Karlberg, O., Canbäck, B., Kurland, C.G., et al., 2001. The dual origin of the yeast mitochondrial proteome. Yeast, 17(3):170-187. http://dx.doi.org/10.1002/1097-0061(200 00930) 17:3<170::AID-YEA25>3.0.CO;2-V

Kather, B., Stingl, K., van der Rest, M.E., et al., 2000. Another unusual type of citric acid cycle enzyme in Helicobacter pylori: the malate:quinone oxidoreductase. J. Bacteriol., 182(11):3204-3209. http://dx.doi.org/10.1128/JB.182.11.3204-3209.2000

Kawakami, R., Sakuraba, H., Goda, S., et al., 2009. Refolding, characterization and crystal structure of $(S)$-malate dehydrogenase from the hyperthermophilic archaeon Aeropyrum pernix. Biochim. Biophys. Acta, 1794(10):1496-1504. http://dx.doi.org/10.1016/j.bbapap.2009.06.014

Kelly, C.A., Nishiyama, M., Ohnishi, Y., et al., 1993. Determinants of protein thermostability observed in the $1.9-\AA$ crystal structure of malate dehydrogenase from the thermophilic bacterium Thermus flavus. Biochemistry, 
32(15):3913-3922.

http://dx.doi.org/10.1021/bi00066a010

Kim, S.Y., Hwang, K.Y., Kim, S.H., et al., 1999. Structural basis for cold adaptation. Sequence, biochemical properties, and crystal structure of malate dehydrogenase from a psychrophile Aquaspirillium arcticum. J. Biol. Chem., 274(17):11761-11767. http://dx.doi.org/10.1074/jbc.274.17.11761

Kono, H., Nishiyama, M., Tanokura, M., et al., 1997. Design of hydrophobic core of Escherichia coli malate dehydrogenase based on the side-chain packing. Pac. Symp. Biocomput., 2:210-221.

Kono, H., Nishiyama, M., Tanokura, M., et al., 1998. Designing the hydrophobic core of Thermus flavus malate dehydrogenase based on the side-chain packing. Protein Eng., 11(1):47-52. http://dx.doi.org/10.1093/protein/11.1.47

Koonin, E.V., Galperin, M.Y., 2003. Evolution of central metabolic pathways: the playground of non-orthologous gene displacement. In: Sequence-Evolution-Function: Computational Approaches in Comparative Genomics. Kluwer Academic, Boston, Chapter 7. http://dx.doi.org/10.1007/978-1-4757-3783-7

Kretzschmar, U., Ruckert, A., Jeoung, J.H., et al., 2002. Malate:quinone oxidoreductase is essential for growth on ethanol or acetate in Pseudomonas aeruginosa. Microbiology, 148(12):3839-3847.

http://dx.doi.org/10.1099/00221287-148-12-3839

Labrou, N.E., Clonis, Y.D., 1997. L-Malate dehydrogenase from Pseudomonas stutzeri: purification and characterization. Arch. Biochem. Biophys., 337(1):103-114. http://dx.doi.org/10.1006/abbi.1996.9748

Langelandsvik, A.S., Steen, I.H., Birkeland, N.K., et al., 1997. Properties and primary structure of a thermostable L-malate dehydrogenase from Archaeoglobus fulgidus. Arch. Microbiol., 168(1):59-67. http://dx.doi.org/10.1007/s002030050470

Lee, B.I., Chang, C., Cho, S.J., et al., 2001. Crystal structure of the MJ0490 gene product of the hyperthermophilic archaebacterium Methanococcus jannaschii, a novel member of the lactate/malate family of dehydrogenases. J. Mol. Biol., 307(5):1351-1362.

http://dx.doi.org/10.1006/jmbi.2001.4532

Madern, D., 2002. Molecular evolution within the L-malate and L-lactate dehydrogenase super-family. J. Mol. Evol., 54(6):825-840. http://dx.doi.org/10.1007/s00239-001-0088-8

Madern, D., Zaccai, G., 2004. Molecular adaptation: the malate dehydrogenase from the extreme halophilic bacterium Salinibacter ruber behaves like a non-halophilic protein. Biochimie, 86(4-5):295-303. http://dx.doi.org/10.1016/j.biochi.2004.04.004

McAlister-Henn, L., 1988. Evolutionary relationships among the malate dehydrogenases. Trends Biochem. Sci., 13(5): 178-181.

http://dx.doi.org/10.1016/0968-0004(88)90146-6
Mendoza, A.P., Servín, L., Flores, M.E., 2009. Malate dehydrogenase of Saccharopolyspora erythraea CA340: purification and effect of carbon source on its synthesis. Rev. Lat. Microbiol., 51(1-2):18-22.

Mernik, N., Lewis, R., Kollarova, M., et al., 1998. Characterization and crystallisation of the malate dehydrogenase from Streptomyces aureofaciens. Gen. Physiol. Biophys., 17(Suppl. 1):49-51.

Meyer, F.M., Gerwig, J., Hammer, E., et al., 2011. Physical interactions between tricarboxylic acid cycle enzymes in Bacillus subtilis: evidence for a metabolon. Metab. Eng., 13(1):18-27. http://dx.doi.org/10.1016/j.ymben.2010.10.001

Mikulášová, D., Kollárová, M., Miginiac-Maslow, M., et al., 1998. Purification and characterization of the malate dehydrogenase from Streptomyces aureofaciens. FEMS Microbiol. Lett., 159(2):299-305. http://dx.doi.org/10.1111/j.1574-6968.1998.tb12875.x

Molenaar, D., van der Rest, M.E., Petrović, S., 1998. Biochemical and genetic characterization of the membraneassociated malate dehydrogenase (acceptor) from Corynebacterium glutamicum. Eur. J. Biochem., 254(2):395-403. http://dx.doi.org/10.1046/j.1432-1327.1998.2540395.x

Molenaar, D., van der Rest, M.E., Drysch, A., et al., 2000. Functions of the membrane-associated and cytoplasmic malate dehydrogenases in the citric acid cycle of Corynebacterium glutamicum. J. Bacteriol., 182(24): 6884-6891. http://dx.doi.org/10.1128/JB.182.24.6884-6891.2000

Musrati, R.A., Kollárová, M., Mernik, N., et al., 1998. Malate dehydrogenase: distribution, function and properties. Gen. Physiol. Biophys., 17(3):193-210.

Naterstad, K., Lauvrak, V., Siverag, R., 1996. Malate dehydrogenase from the mesophile Chlorobium vibrioforme and from the mild thermophile Chlorobium tepidum: molecular cloning, construction of a hybrid, and expression in Escherichia coli. J. Bacteriol., 178(24):7047-7052.

Nicholls, D., Miller, J., Scawen, M., et al., 1992. The importance of arginine 102 for the substrate specificity of Escherichia coli malate dehydrogenase. Biochem. Biophys. Res. Commun., 189(2):1057-1062. http://dx.doi.org/10.1016/0006-291X(92)92311-K

Nishiyama, M., Matsubara, N., Yamamoto, K., et al., 1986. Nucleotide sequence of the malate dehydrogenase gene of Thermus flavus and its mutation directing an increase in enzyme activity. J. Biol. Chem., 261(30):14178-14183.

Nishiyama, M., Shimada, K., Horinouchi, S., et al., 1991. Role of threonine 190 in modulating the catalytic function of malate dehydrogenase from a thermophile Thermus flavus. J. Biol. Chem., 266(22):14294-14299.

Nishiyama, M., Birktoft, J.J., Beppu, T., 1993. Alteration of coenzyme specificity of malate dehydrogenase from Thermus flavus by site-directed mutagenesis. J. Biol. Chem., 268(7):4656-4660.

Nishiyama, M., Kinoshita, M., Kudo, H., et al., 1996. Enhancement of the turnover number of thermostable malate 
dehydrogenase by deleting hydrogen bonds around the catalytic site. Biochem. Biophys. Res. Commun., 225(3): 844-848. http://dx.doi.org/10.1006/bbrc.1996.1261

Oh, T.J., Kim, I.G., Park, S.Y., et al., 2002. NAD-dependent malate dehydrogenase protects against oxidative damage in Escherichia coli K-12 through the action of oxaloacetate. Environ. Toxicol. Pharmacol., 11(1):9-14. http://dx.doi.org/10.1016/S1382-6689(01)00093-X

Öhman, R., Ridell, M., 1996. Purification and characterisation of isocitrate dehydrogenase and malate dehydrogenase from Mycobacterium tuberculosis and evaluation of their potential as suitable antigens for the serodiagnosis of tuberculosis. Tuber. Lung Dis., 77(5):454-461. http://dx.doi.org/10.1016/S0962-8479(96)90120-3

Park, H.S., Kilbane II, J.J., 2004. Gene expression studies of Thermus thermophilus promoters $\mathrm{P} d n a K, \mathrm{P} a r G$ and Pscs-mdh. Lett. Appl. Microbiol., 38(5):415-422. http://dx.doi.org/10.1111/j.1472-765X.2004.01512.x

Park, S.J., Cotter, P.A., Gunsalus, R.P., 1995. Regulation of malate dehydrogenase $(m d h)$ gene expression in Escherichia coli in response to oxygen, carbon, and heme availability. J. Bacteriol., 177(22):6652-6656.

Pitson, S.M., Mendz, G.L., Srinivasan, S., et al., 1999. The tricarboxylic acid cycle of Helicobacter pylori. Eur. J. Biochem., 260(1):258-267. http://dx.doi.org/10.1046/j.1432-1327.1999.00153.x

Rolstad, A.K., Howland, E., Sirevåg, R., 1988. Malate dehydrogenase from the thermophilic green bacterium Chloroflexus aurantiacus: purification, molecular weight, amino acid composition, and partial amino acid sequence. $J$. Bacteriol., 170(7):2947-2953.

Sidhu, N.S., Delbaere, L.T., Sheldrick, G.M., 2011. Structure of a highly $\mathrm{NADP}^{+}$-specific isocitrate dehydrogenase. Acta Cryst., D67(Pt 10):856-869. http://dx.doi.org/10.1107/S0907444911028575

Singh, R., Lemire, J., Mailloux, R.J., et al., 2008. A novel strategy involved anti-oxidative defense: the conversion of NADH into NADPH by a metabolic network. PLoS ONE, 3(7):e2682. http://dx.doi.org/10.1371/journal.pone.0002682

Smith, K., Sundaram, T.K., Kernick, M., 1984. Malate dehydrogenases from actinomycetes: structural comparison of Thermoactinomyces enzyme with other actinomycete and Bacillus enzymes. J. Bacteriol., 157(2):684-687.

Sundaram, T.K., Wright, I.P., Wilkinson, A.E., 1980. Malate dehydrogenase from thermophilic and mesophilic bacteria. Molecular size, subunit structure, amino acid composition, immunochemical homology, and catalytic activity. Biochemistry, 19(10):2017-2022. http://dx.doi.org/10.1021/bi00551a002

Tayeh, M.A., Madigan, M.T., 1987. Malate dehydrogenase in phototrophic purple bacteria: purification, molecular weight, and quaternary structure. J. Bacteriol., 169(9): 4196-4202.
Thompson, H., Tersteegen, A., Thauer, R.K., et al., 1998. Two malate dehydrogenases in Methanobacterium thermoautotrophicum. Arch. Microbiol., 170(1):38-42. http://dx.doi.org/10.1007/s002030050612

Tomita, T., Fushinobu, S., Kuzuyama, T., et al., 2005. Crystal structure of NAD-dependent malate dehydrogenase complexed with NADP(H). Biochem. Biophys. Res. Comm., 334(2):613-618. http://dx.doi.org/10.1016/j.bbrc.2005.06.133

van der Rest, M.E., Frank, C., Molenaar, D., 2000. Functions of the membrane-associated and cytoplasmic malate dehydrogenases in the citric acid cycle of Escherichia coli. J. Bacteriol., 182(24):6892-6899. http://dx.doi.org/10.1128/JB.182.24.6892-6899.2000

van Kuijk, B.L.M., Stams, A.J.M., 1996. Purification and characterization of malate dehydrogenase from the syntrophic propionate-oxidizing bacterium strain MPOB. FEMS Microbiol. Lett., 144(2-3):141-144. http://dx.doi.org/10.1111/j.1574-6968.1996.tb08520.x

Vogel, R.F., Entian, K.D., Mecke, D., 1987. Cloning and sequence of the $m d h$ structural gene of Escherichia coli coding for malate dehydrogenase. Arch. Microbiol., 149(1):36-42. http://dx.doi.org/10.1007/BF00423133

Wang, Z.D., Wang, B.J., Ge, Y.D., et al., 2011. Expression and identification of a thermostable malate dehydrogenase from multicellular prokaryote Streptomyces avermitilis MA-4680. Mol. Biol. Rep., 38(3):1629-1636. http://dx.doi.org/10.1007/s11033-010-0273-1

Welch, T.J., Bartlett, D.H., 1997. Cloning, sequencing and overexpression of the gene encoding malate dehydrogenase from the deep-sea bacterium Photobacterium species strain SS9. Biochim. Biophys. Acta, 1350(1):41-46. http://dx.doi.org/10.1016/S0167-4781(96)00200-X

Wilks, H.M., Hart, K.W., Feeney, R., et al., 1988. A specific, highly active malate dehydrogenase by redesign of a lactate dehydrogenase framework. Science, 242(4885):1541-1544. http://dx.doi.org/10.1126/science.3201242

Wise, D.J., Anderson, C.D., Anderson, B.M., 1997. Purification and kinetic characterization of Haemophilus parasuis malate dehydrogenase. Arch. Biochem. Biophys., 344(1): 176-183. http://dx.doi.org/10.1006/abbi.1997.0186

Wu, H., Li, Z.M., Zhou, L., et al., 2007. Improved succinic acid production in the anaerobic culture of an Escherichia coli pflB ldhA double mutant as a result of enhanced anaplerotic activities in the preceding aerobic culture. Appl. Environ. Microbiol., 73(24):7837-7843. http://dx.doi.org/10.1128/AEM.01546-07

Wynne, S.A., Nicholls, D.J., Scawen, M.D., et al., 1996. Tetrameric malate dehydrogenase from a thermophilic $\mathrm{Ba}$ cillus: cloning, sequence and overexpression of the gene encoding the enzyme and isolation and characterization of the recombinant enzyme. Biochem. J., 317(1):235-245. http://dx.doi.org/10.1042/bj3170235

Yano, T., Li, L.S., Weinstein, E., et al., 2006. Steady-state 
kinetics and inhibitory action of antitubercular phenothiazines on Mycobacterium tuberculosis type-II NADHmenaquinone oxidoreductase (NDH-2). J. Biol. Chem., 281(17):11456-11463.

http://dx.doi.org/10.1074/jbc.M508844200

Yennaco, L.J., Hu, Y., Holden, J.F., 2007. Characterization of malate dehydrogenase from the hyperthermophilic archaeon Pyrobaculum islandicum. Extremophiles, 11(5): 741-746.

http://dx.doi.org/10.1007/s00792-007-0081-2

\section{中文概要}

题 目: 微生物苹果酸脱氢酶的功能、动力学特征、晶体 结构以及调控

概 要: 苹果酸脱氢酶 $(\mathrm{MDH})$ 广泛存在于动物、植物以 及微生物体内, 是生物体进行糖代谢的关键酶之
一。在辅酶 I $\left(\mathrm{NAD}^{+}\right)$或辅酶 II $\left(\mathrm{NADP}^{+}\right)$的作 用下, 能够催化草酰乙酸和苹果酸之间相互转 化。虽然目前真核微生物中 MDH已被广泛研究, 但是对原核生物中的这种酶却鲜有报道。因此, 有必要对 MDH 的相关研究信息进行综述, 以期 更好地了解这种酶的功能。本文综述了细菌相关 研究的各种数据信息, 进一步挖掘 $\mathrm{MDH}$ 的分子 多样性, 包括分子量、低聚态、辅因子与底物的 结合力, 以及酶反应方向的差异等。通过对不同 细菌来源的 MDH 的晶体结构的分析, 可鉴别底 物与辅因子结合的部位以及形成二聚体的重要 残基。对这些结构信息的了解将有利于指导研究 人员对酶的结构进行修饰从而提高其催化能力, 比如增加酶的活性、辅助因子的结合能力、底物 特异性和热稳定性等。另外, 本文通过分析比较 $\mathrm{MDH}$ 系统发生树的重建, 将其蛋白超家族分成 两个主分支, 同时在古生菌、细菌和真核微生物 等不同细胞的 $\mathrm{MDH}$ 之间建立联系。

关键词: 苹果酸脱氢酶; 碳代谢; 三羧酸循环 